\title{
Reliability-based assessment of the partial factor for shear design of fibre reinforced concrete members without shear reinforcement
}

\author{
Jesús Miguel Bairán $(\mathbb{D} \cdot$ Nikola Tošić $\mathbb{D} \cdot$ Albert de la Fuente $\mathbb{C}$
}

Received: 24 January 2021/Accepted: 12 August 2021/Published online: 3 September 2021

(C) The Author(s) 2021

\begin{abstract}
Fibre reinforced concrete (FRC) is increasingly used for structural purposes owing to its many benefits, especially in terms of improved overall sustainability of FRC structures relative to traditional reinforced concrete (RC). Such increased structural use of FRC requires safe and reliable models for its design in ultimate limit states (ULS). Particularly important are models for shear strength of FRC members without shear resistance due to the potential of brittle failure. The fib Model Code 2010 contains a model for the shear strength of FRC members without shear reinforcement and the same partial factor accepted for RC structures is accepted for FRC elements. This approach, however, is potentially on the unsafe side since the uncertainties of some designdetermining mechanical properties of FRC (i.e., residual flexural strength) are larger than those for RC. Therefore, in this study, a comprehensive reliability-based calibration of the partial factor $\gamma_{c}$ for the shear design of FRC members without shear reinforcement according to the fib Model Code 2010 model is performed. As a first step, the model error $\delta$ is assessed on 332 experimental results. Then, a parametric analysis of 700 cases is performed and a relationship between the target failure probability $\beta_{\mathrm{R}}$
\end{abstract}

J. M. Bairán · N. Tošić $(\bowtie)$ · A. de la Fuente

Civil and Environmental Engineering Department,

Universitat Politècnica de Catalunya (UPC), Jordi Girona

1-3, 08034 Barcelona, Spain

e-mail: nikola.tosic@upc.edu and $\gamma_{c}$ is established. The results demonstrate that the current model together with the prescribed value of $\gamma_{c}=1.50$ does not comply with the failure probabilities accepted for the different consequences of failure of FRC members over a 50-year service life. Therefore, changes to the shear resistance model are proposed in order to achieve the target failure probabilities.

Keywords Fiber reinforced concrete $\cdot$ Beam . Reliability $\cdot$ Safety format $\cdot$ Database $\cdot$ Design $\cdot$ FORM

\section{Introduction}

Significant advances in research on fibre reinforced concrete (FRC) over the last 20 years have led to its increasing use in structural applications. FRC is progressively viewed as a more sustainable alternative to traditional reinforced concrete (RC) for some structural applications, considering all three pillars of sustainability: economic, environmental, and social [1-3]. Owing to this, and the regulation of the material in national and international guidelines, the scope of FRC applications has expanded over time to cover ground-supported slabs $[4,5]$, pavements [6, 7], tunnel linings [8-12], and in recent years, bridge decks [13], coupling beams [14], and flat slabs [15-18]. Such a wide range of applications brings with it the need for 
safe and reliable structural design tools oriented to FRC, covering both ultimate limit states (ULS) and serviceability limit states (SLS). Considering structural safety and reliability, primary importance falls on ULS design, namely, FRC design for flexure and shear. While FRC flexural design models have been comprehensively assessed from a reliability standpoint [19], an equivalent assessment of FRC shear design is still incomplete.

The limited knowledge available regarding the reliability of FRC design is expectable, considering the complexities and uncertainties associated with shear design. The significance of shear resistance has attracted the attention of researchers and practitioners for decades [20] with different empirical, semiempirical and theoretical models having been proposed. Particularly, members without shear reinforcement have been of interest, as the substitution of traditional shear reinforcement is an attractive application of FRC for industry, thereby allow the reduction of labour and increasing productivity. However, this application comes with numerous uncertainties owing to the possibility of a brittle failure mode in shear; at the same time, modelling it has proven to be a complex challenge [21]. For example, the current version of Eurocode 2 (EC2) [22] contains an empirical model for the shear strength of RC members without shear reinforcement, whereas the fib Model Code 2010 (MC2010) [23] proposes a physical model based on the Modified Compression Field Theory [24]. Importantly, the performance of shear models for RC members without shear reinforcement exhibits a large scatter when compared with experimental results [25-27]. The "model error" $\delta$ (the ratio between actual behaviour/shear strength measured in experiments and shear strength predicted by models) is typically found to have a coefficient of variation $(\mathrm{CoV})>20 \%$. This has significant implications for shear design results.

In terms of the shear resistance of FRC elements, FRC members without shear reinforcement are the most representative of practical applications (e.g., underground supported floors, precast segmental linings for TBM tunnels and sewerage concrete pipes). This is a case in which fibres can provide the greatest benefit, as these are activated at ULS once a critical shear crack appears, and act as a type of "distributed reinforcement" [28]. So far, the majority of the research, and consequently design recommendations and codes, have focused on steel fibre reinforced concrete (SFRC). For example, Lantsoght [29] compiled a database of 488 results reported in literature on SFRC beams tested for shear strength. As expected, the majority of theoretical work on FRC shear has also been focused on SFRC [30-32]. Nonetheless, shear models originally derived for SFRC were reported to be compatible with polymeric fibre reinforced concrete (PFRC) [33, 34].

The currently proposed model for SFRC shear strength in MC2010 is the result of work by Minelli et al. [31,32,35]. The model is based on the empirical EC2 formulation of shear strength for members without shear reinforcement. Although fibres provide several contributions to shear strength-toughness, aggregate interlock, improved bending strength of struts, increased dowel action of the longitudinal reinforcement [28]—for simplicity, the proposed MC2010 model considers only the contribution of the fibres through the pull-out mechanism. Nonetheless, the model was tested against various experimental results with varying results: Lantsogh [29] found a model error with a mean and CoV of 1.24 and $29 \%$, respectively; Cuenca et al. [36] found a mean and CoV of 1.08 and 22\%, respectively; and Marí et al. [37] found a mean and $\mathrm{CoV}$ of 1.04 and 23\%, respectively. The differences in the model errors found between researchers can principally be attributed to the databases they used and their sizes as well as the values of residual strengths of FRC; e.g. Lantsogh [29] used an analytic expression to predict residual strength, whereas Cuenca et al. [36] relied on experimentally reported values. While these results are commensurable with model uncertainties for RC members without shear reinforcement, these are inconclusive about the reliability of SFRC shear design since the probability of failure remains unquantified. The proposed model is based on an SFRC partial factor $\gamma_{c}=1.50$, accepted by the $f b$ Technical Council maintaining a consistent value for concrete, without apparently developing a full probabilistic analysis (this was not reported into the MC2010 background documentation). Considering the high scatter associated with SFRC tensile/flexural residual strength, it is unclear in advance that target reliability indexes $(\beta)$ or, equivalently, failure probabilities prescribed by MC2010 are achieved by the current model, especially considering that $\gamma_{\mathrm{c}}=1.50$ 
was found to be insufficient in some cases even for flexural design [19].

The aim of this study is to perform a probabilistic analysis of the MC2010 model for the shear strength of FRC members without shear reinforcement and calibrate partial factor $\gamma_{\mathrm{c}}$ required for achieving codeprescribed failure probabilities $P_{\mathrm{f}}$ according to different consequence classes. For this purpose, first, the model error was determined on a database of experimental results. Then, a parametric study was performed using the First Order Reliability Method (FORM) considering different probability distributions and parameters of input variables. Finally, based on the results, the FRC partial factor $\gamma_{c}$ is calibrated based on the target reliability index $\beta$ and failure probability $P_{\mathrm{f}}$. As such, this study is among the first to analyse FRC shear design using a reliability-based approach. Therefore, the results and conclusions presented herein are expected to provide a contribution for future revisions of the national and international design codes for FRC members, such as the currently ongoing efforts on the preparation of the fib Model Code 2020 [38].

\section{Description of shear resistance model and assessment of model error}

\subsection{Shear design of FRC elements according} to the $f i b$ Model Code 2010

According to section 7.7.3.2.2 of MC2010, shear strength of FRC members "with conventional longitudinal reinforcement and without shear reinforcement" is given by expression (7.7-5) of MC2010 [23]:

$V_{\mathrm{Rd}, \mathrm{F}}=\left\{\frac{0.18}{\gamma_{\mathrm{c}}} \cdot k \cdot\left[100 \cdot \rho_{\mathrm{l}} \cdot\left(1+7.5 \cdot \frac{f_{\mathrm{Ftuk}}}{f_{\mathrm{ctk}}}\right) \cdot f_{\mathrm{ck}}\right]^{1 / 3}+0.15 \cdot \sigma_{\mathrm{cp}}\right\} \cdot b_{\mathrm{w}} \cdot d$

where $V_{\mathrm{Rd}, \mathrm{F}}$ is the shear strength in $(\mathrm{N})$;

$\gamma_{c}$ is the partial factor for concrete;

$k$ is a factor considering the size effect, determined as

$k=1+\sqrt{\frac{200}{d}} \leq 2.0$

$d$ is the effective depth in (mm);

$\rho_{1}$ is the longitudinal reinforcement ratio defined as
$\rho_{1}=\frac{A_{\mathrm{sl}}}{b_{\mathrm{w}} \cdot d}$

$b_{\mathrm{w}}$ is the smallest width of the cross-section in the tensile zone in $(\mathrm{mm})$;

$f_{\text {Ftuk }}$ is the characteristic value of the ultimate residual tensile strength of FRC, considering a crack width $w_{\mathrm{u}}=1.5 \mathrm{~mm}$, according to Eqs. (5.6-6) of MC2010 [23]:

$f_{\mathrm{Ftu}}=f_{\mathrm{Fts}}-\frac{w_{\mathrm{u}}}{\mathrm{CMOD}_{3}} \cdot\left(f_{\mathrm{Fts}}-0.5 \cdot f_{\mathrm{R} 3}+0.2 \cdot f_{\mathrm{R} 1}\right) \geq 0$

$\mathrm{CMOD}_{3}$ is the crack mouth opening displacement (CMOD) of $2.5 \mathrm{~mm}$ per EN 14651 [39];

$f_{\mathrm{Ftu}}$ is the mean value of the ultimate residual tensile strength of FRC, $f_{\mathrm{Fts}}$ is the mean FRC serviceability residual strength equal to $0.45 \cdot f_{\mathrm{R} 1 \mathrm{k}}$;

$f_{\mathrm{R} 1}$ is the mean FRC residual strength corresponding to $\mathrm{CMOD}=0.5 \mathrm{~mm}$;

$f_{\mathrm{R} 3}$ is the mean FRC residual strength corresponding to $\mathrm{CMOD}=2.5 \mathrm{~mm} ; f_{\text {ctk }}$ is the characteristic value of the tensile strength of concrete in (MPa);

$f_{\mathrm{ck}}$ is the characteristic value of the compressive strength of concrete in (MPa) defined as $f_{\mathrm{cm}}-8 \mathrm{MPa}$, where $f_{\mathrm{cm}}$ is the mean compressive strength;

$\sigma_{\mathrm{cp}}$ is the average stress acting on the concrete cross-section $A_{\mathrm{c}}\left(\mathrm{mm}^{2}\right)$ due to an axial force $N_{\mathrm{Ed}}$ (N) caused by loading or prestress $\left(N_{\mathrm{Ed}}\right.$ is positive for compression), i.e. $\sigma_{\mathrm{cp}}=N_{\mathrm{Ed}} / A_{\mathrm{c}}<0.2 \cdot f_{\mathrm{cd}}$, where $f_{\mathrm{cd}}$ is the design compressive strength.

In order to calculate $f_{\text {Ftuk }}$ from Eq. (4), the mean values of $f_{\mathrm{Fts}}, f_{\mathrm{R} 1}$ and $f_{\mathrm{R} 3}$ should be replaced with their characteristic values $f_{\mathrm{Ftsk}}, f_{\mathrm{R} 1 \mathrm{k}}$ and $f_{\mathrm{R} 3 \mathrm{k}}$, respectively, as an approximation.

It can be noted that Eq. (1) is fully based on the EC2 [22] expression for shear strength of RC members without shear reinforcement:

$$
V_{\mathrm{Rd}, \mathrm{c}}=\left\{C_{\mathrm{Rd}, \mathrm{c}} \cdot k \cdot\left[100 \cdot \rho_{1} \cdot f_{\mathrm{ck}}\right]^{1 / 3}+0.15 \cdot \sigma_{\mathrm{cp}}\right\} \cdot b_{\mathrm{w}} \cdot d
$$

where $C_{\mathrm{Rd}, \mathrm{c}}$ is a coefficient equal to $0.18 / \gamma_{\mathrm{c}}$ as in Eq. (1); As in EC2, the shear resistance $V_{\mathrm{Rd}, \mathrm{F}}$ cannot be smaller than a minimum value $V_{\mathrm{Rd}, \mathrm{F}, \min }$ given by Eqs. (6) and (7):

$V_{\mathrm{Rd}, \mathrm{F}, \text { min }}=\left(v_{\min }+0.15 \cdot \sigma_{\mathrm{cp}}\right) \cdot b_{\mathrm{w}} \cdot d$

where 
$v_{\min }=0.035 \cdot k^{3 / 2} \cdot f_{\mathrm{ck}}^{1 / 2}$

The only difference between Eqs. (1) and (5) is the expression $\left(1+7.5 \cdot f_{\mathrm{Ftuk}} / f_{\mathrm{ctk}}\right)$. In this way, fibres are taken into account as a type of "distributed reinforcement" whose equivalent reinforcement ratio is given by $\left(7.5 \cdot f_{\text {Ftuk }} / f_{\text {ctk }}\right) \cdot \rho_{1}[28]$. With this expression, the contribution of fibres increases with increasing reinforcement ratio. As in the case of $\mathrm{RC}$ beams, using this expression, FRC beams without longitudinal reinforcement or prestress would also have no shear resistance and Eq. (6) would become governing. Importantly, in EC2 in Eq. (5) explicitly limits the value of $\rho_{1}$ to be used for calculating $V_{\mathrm{Rd}, \mathrm{c}}$ to 0.02 (2\%). However, MC2010 in Eq. (1) does not explicitly impose such a limit, although considering the origin of the expression, it seems justified to maintain it.

It should also be noted that a partial factor associated to concrete without fibres is currently used, i.e. $\gamma_{c}=1.50$. Furthermore, it is left undefined which characteristic value of tensile strength should be used. Finally, although not explicitly stated in MC2010, the limitations of EC2 should be followed, according to which a maximum value of $\rho_{1}=0.02$ should be used in Eqs. (1) and (5) [22].

During the development of the model, other factors were considered as well, such as the shear span-toeffective depth ratio $a / d$, but this was abandoned for achieving greater simplicity [35].

\subsection{Assessment of model uncertainty}

\subsubsection{Description of experimental results database}

In this study, the database of experiments on SFRC beams without shear reinforcement, compiled by Lantsoght [29] and freely available online [40] was used. The database is described in detail by Lantsoght [29] and only the main points are stated here. Originally, the database consisted of 488 results on SFRC beams with longitudinal reinforcement and without shear reinforcement, collected from 65 individual studies. The parameter range of the original database is shown in Table 1 under the "Original database" column. Lantsoght [29] explains all instances of missing information as well as the procedures and assumptions adopted for approximating missing information. This included, for example: geometry of the support plates, overhang of the beams (i.e. total length vs. clear span), conversion of concrete strength from cubes to cylinders, among others.

All beams in the database were simply supported tested in either three- or four-point bending; the majority of beams have rectangular cross-sections although specimens from four studies were T-beams, specimens from two studies were I-beams and specimens from one study were non-prismatic beams. Importantly, residual strength was not a parameter reported in the database, because not all studies reported these values, for a variety of reasons. However, a large number of fibre properties is reported-type, volume, aspect ratio and tensile strength. As for fibre types, the database contains SFRC beams with hooked, crimped, straight smooth, mixed (hooked + straight), fibres with a flat end, flat fibres, round fibres, mill-cut fibres, fibres of straight mild steel, brass-coated high strength steel fibres, chopped fibres with butt ends, recycled fibres, and corrugated fibres [29].

Regarding the parameter values in the original database, these cover a very wide range, even outside the scope of practical applications in some cases. Therefore, in this study, the following filtering criteria were applied to the database in order to obtain a better match between the tested beams and practical SFRC applications:

1. Concrete classes between $\mathrm{C} 12$ and $\mathrm{C} 120$ were considered (mean compressive strengths between 20 and $128 \mathrm{MPa}$ );

2. Only beams with a longitudinal reinforcement ratio smaller than $4 \%$ were considered;

3. Only beams with a clear shear span-to-effective depth ratio larger than 2.0 were considered.

Criterion (1) was applied as classes C12 and C120 are the lower and upper concrete classes as defined by MC2010 [23]. As those refer to the characteristic compressive strength $f_{\text {ck }}$, beams were excluded based on the reported mean concrete strength $f_{\mathrm{cm}}=f_{\text {ck- }}$ $+8 \mathrm{MPa}$, i.e. beams with $f_{\mathrm{cm}}$ below 20 and above $128 \mathrm{MPa}$ were excluded. This reduced the number of beams from 488 to 477 (11 excluded).

Criterion (2) was introduced as some of the beams had very large reinforcement ratios unrepresentative of practical applications, as well as because EC2 [22] limits $\rho_{1}$ to $4 \%$. This criterion further reduced the number of beams from 477 to 443 (34 excluded). 
Table 1 Parameter ranges of the SFRC beam database

\begin{tabular}{|c|c|c|c|c|}
\hline \multirow[t]{2}{*}{ Parameter } & \multicolumn{2}{|c|}{ Original database [29] $n=488$} & \multicolumn{2}{|c|}{ Filtered database $n=332$} \\
\hline & Min & Max & Min & Max \\
\hline$b_{\mathrm{w}}(\mathrm{mm})$ & 50 & 610 & 50 & 610 \\
\hline$h(\mathrm{~mm})$ & 100 & 1220 & 100 & 1220 \\
\hline$d(\mathrm{~mm})$ & 85 & 1118 & 85 & 1118 \\
\hline$l_{\text {span }}(\mathrm{mm})$ & 204 & 7823 & 459 & 7823 \\
\hline ald (-) & 0.46 & 6.00 & 2.22 & 6.00 \\
\hline$a_{\mathrm{v}} / d(-)$ & 0.20 & 5.95 & 2.00 & 5.95 \\
\hline$\rho_{1}(\%)$ & $0.37 \%$ & $5.72 \%$ & $0.37 \%$ & $3.70 \%$ \\
\hline$f_{\mathrm{y}}(\mathrm{MPa})$ & 276 & 900 & 276 & 610 \\
\hline$f_{\mathrm{cm}}(\mathrm{MPa})$ & 9.8 & 215.0 & 20.2 & 111.5 \\
\hline$V_{\mathrm{f}}(\%)$ & $0.2 \%$ & $4.5 \%$ & $0.2 \%$ & $4.5 \%$ \\
\hline$\lambda(-)$ & 25 & 191 & 25 & 191 \\
\hline$f_{\mathrm{uf}}(\mathrm{MPa})$ & 260 & 4913 & 260 & 4913 \\
\hline
\end{tabular}

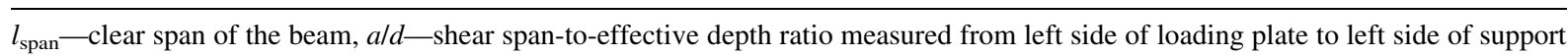
$a_{\mathrm{v}} / d$-clear shear span-to-effective depth ratio measured from face of loading plate to face of support, $f_{\mathrm{y}}$-yield strength of steel reinforcement

$V_{\mathrm{f}}$-fibre volume fraction, $\lambda$-fibre aspect ratio (ratio of fibre length to diameter)

$f_{\text {uf }}$-tensile strength of fibres

Finally, $a_{\mathrm{v}} / d$ was limited to values above 2 because a different resisting mechanism is activated in these cases, consisting in the direct transfer of load to the support for values below 2 (following the EC2 procedure, in such cases the shear strength is multiplied by $\left.a_{\mathrm{v}} /(2 \cdot d)\right)$. However, in this research, those cases were filtered from the database to restrict the analysis to the standard cases of Eq. (1). This finally reduced the number of beams from 443 to 332 (111 excluded). Therefore, it is concluded that the strictest criterion was (3). The ranges of parameter values for the filtered database are provide in Table 1 under the "Filtered database" heading and histograms for the main parameters of the filtered database are shown in Fig. 1.

The distribution of parameters shown in Fig. 1 reveals that the majority $(91.0 \%)$ of beams were normal strength concrete $\left(f_{\mathrm{cm}}<70 \mathrm{MPa}\right)$ with effective depths between 100 and $500 \mathrm{~mm}$ (87.0\%). The longitudinal reinforcement ratios were relatively large, mostly between 1.0 and $3.5 \%$ (94.6\%). The fibre volume fraction of 329 out of the 332 beams $(99 \%)$ was below $2.0 \%\left(160 \mathrm{~kg} / \mathrm{m}^{3}\right)$ and for 296 beams $(89 \%)$ it was below $1.5 \%\left(120 \mathrm{~kg} / \mathrm{m}^{3}\right)$. The latter volume fraction could be the lower bound beyond which strain-hardening composites are obtained. Finally, the fibre aspect ratios were mostly between 50 and $100(74.7 \%)$, also typical for steel fibres.

\subsubsection{Model uncertainty}

The experimental values of residual strengths $f_{\mathrm{R} 1}$ and $f_{\mathrm{R} 3}$ were not provided in the database compiled by Lantsoght [29] since, most probably, these were only partially reported in the original sources. Consequently, Lantsoght estimated the values of $f_{\mathrm{R} i}$ (where $i$ is 1 or 3 ) by resorting to the formulation experimentally calibrated by Thomas and Ramaswamy [41] for assessing the modulus of rupture (MOR) of SFRCs prisms $(100 \times 100 \times 500 \mathrm{~mm})$ tested according the standard IS: 516 BIS [42]. This approach can be assumed as valid as a first approximation since the specimen is subjected to flexure, this leading to the activation of the fibres once cracking occurs; however, it must be remarked that MOR and $f_{\mathrm{R} i}$ have different physical meanings-and refer to different crack widths - and that the test configuration and procedure also differ. 

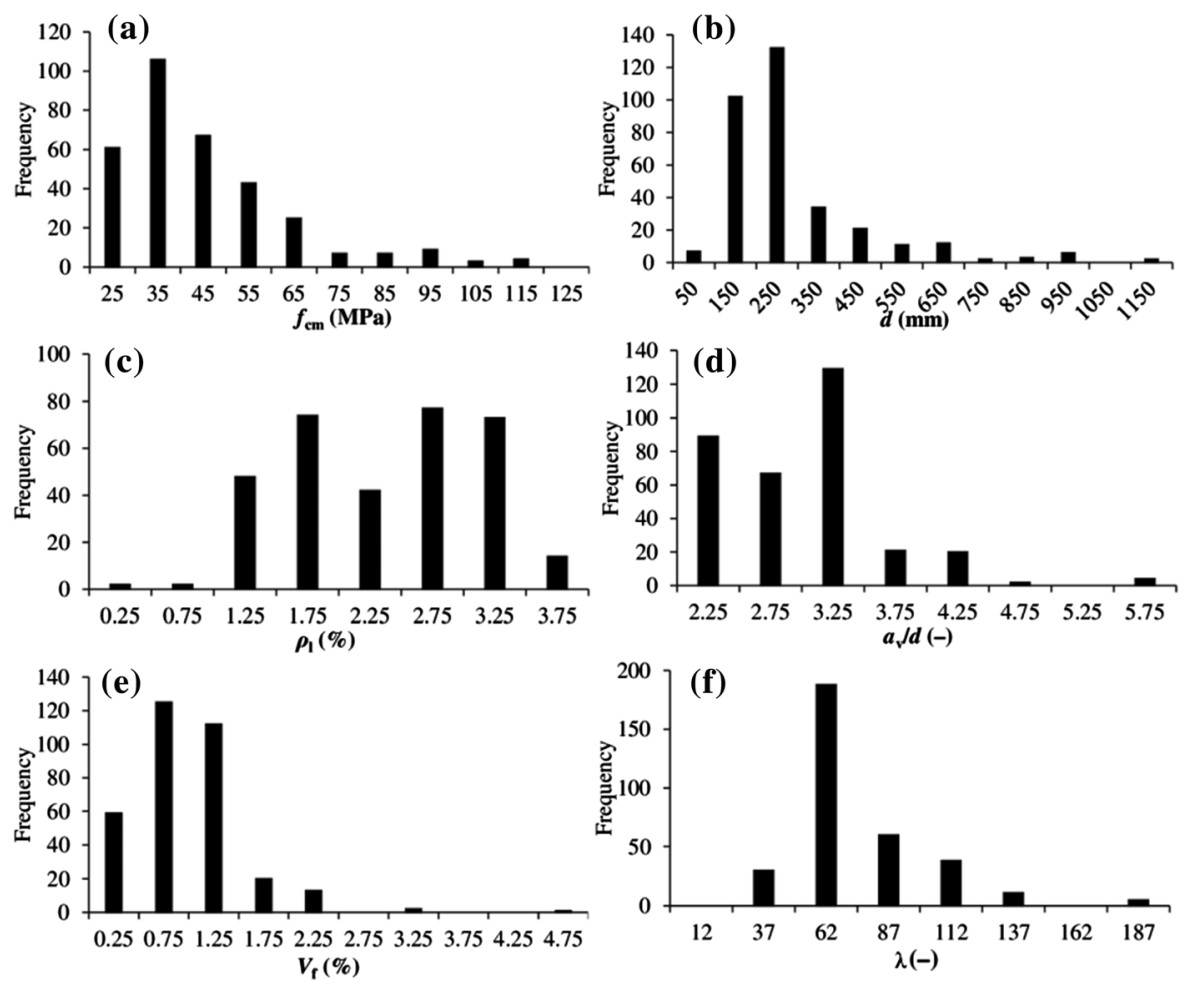

Fig. 1 Distribution of parameters in the filtered database, i.e., frequency relative to a concrete compressive strength, $\mathbf{b}$ longitudinal reinforcement ratio, $\mathbf{c}$ effective depth, $\mathbf{d}$ clear shear span-to-effective depth ratio, $\mathbf{e}$ fibre volume fraction, and $\mathbf{f}$ fibre aspect ratio

Alternatively, in this research the values of $f_{\mathrm{R} i}$ were estimated by using the regressions presented in Fig. $2 \mathrm{a}$ (for $f_{\mathrm{R} 3}$ ) and $\mathrm{b}$ (for $f_{\mathrm{R} 1}$ ). These were derived from a statistical analysis of an extensive database consisting of EN 14651:2005 [39] tests of SFRC notched-beams $(150 \times 150 \times 600 \mathrm{~mm})$ reported by Venkateshwaran et al. [43], Tiberti et al. [44], Moreno et al. [45], as well as other experimental programs conducted at the Laboratori de Tecnologia d'Estructures i Materials (LATEM) of Universitat Politècnica de Catalunya (UPC). This database includes a large variety of concrete mixes, covering a range of compressive strength $\left(f_{\mathrm{cm}}\right)$ 15-117 MPa, volume fraction of fibers $\left(V_{\mathrm{f}}\right) 0.33-2.52 \%$, fiber aspect ratios $(\lambda) 35-110$, fiber tensile strength $\left(f_{\text {uf }}\right) 1000$ to $3000 \mathrm{~N} / \mathrm{mm}^{2}$ and fiber modulus of elasticity $\left(E_{\mathrm{f}}\right)$ from 190,000 to $210,000 \mathrm{~N} /$ $\mathrm{mm}^{2}$. From Fig. 2, a suitable fit can be seen between the proposed linear regressions and the observed data, the coefficients of determination $\left(R^{2}\right)$ being equal to 0.90 and 0.75 for predictions of $f_{\mathrm{R} 1}$ and $f_{\mathrm{R} 3}$, respectively.

Considering the above-stated, it should be noted that the error model calculated in this study does not explicitly consider the uncertainties introduced by the modelling of residual strengths $f_{\mathrm{R} 1}$ and $f_{\mathrm{R} 3}$ through the proposed regressions.

The derived regressions were then used to calculated the model error $\delta$ of the Eq. (1), defined as

$\delta=V_{\text {experiment }} / V_{\text {model }}$

For this purpose, the partial factor $\gamma_{c}$ was eliminated from Eq. (1) and mean values of material properties were used. In other words, values of mean compressive strength $f_{\mathrm{cm}}$ reported in the database were used, whereas residual strengths $f_{\mathrm{R} 1}$ and $f_{\mathrm{R} 3}$ were first calculated based on the regressions in Fig. 2 and then used to calculate $f_{\mathrm{Ftu}}$ based on Eq. (4). As for mean tensile strength $f_{\mathrm{ct}}$, it was calculated based on the MC2010 expressions:

$f_{\mathrm{ct}}= \begin{cases}0.3 \cdot f_{\mathrm{ck}}^{2 / 3} ; & \text { for } f_{\mathrm{ck}} \leq 50 \mathrm{MPa} \\ 2.12 \cdot \ln \left(1+0.1 \cdot\left(f_{\mathrm{ck}}+8\right)\right) ; & \text { for } f_{\mathrm{ck}}>50 \mathrm{MPa}\end{cases}$

The upper limit of $2 \%$ was applied to the longitudinal reinforcement ratio $\rho_{1}$. Finally, all beams were 

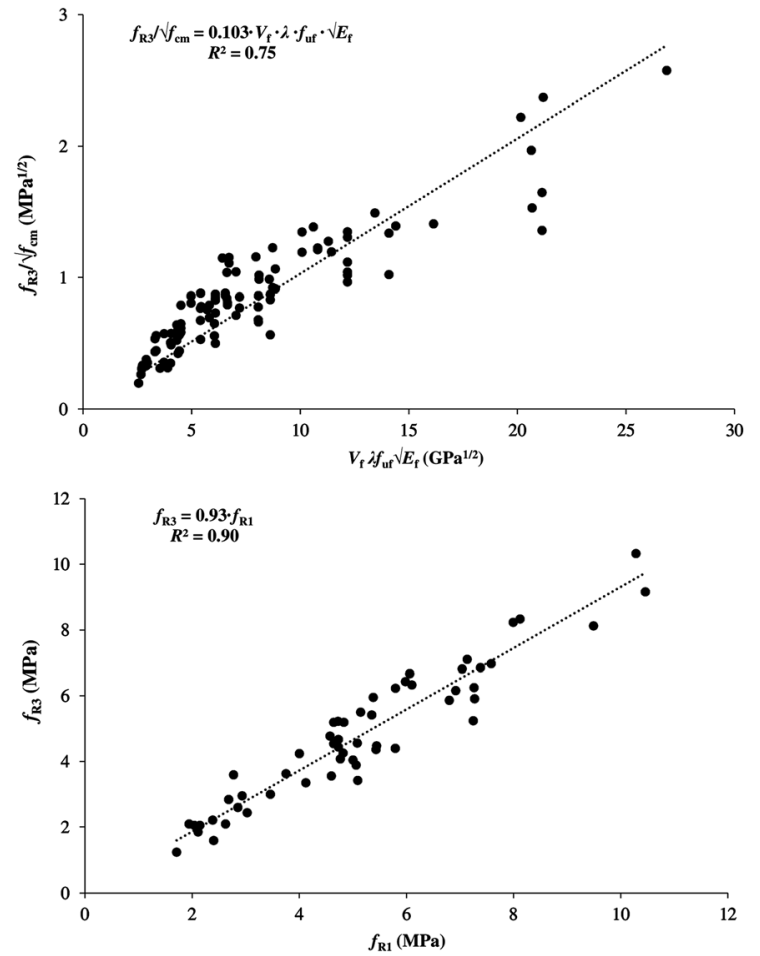

Fig. 2 Correlations used to assess $\mathrm{f}_{\mathrm{R} 3}$ (top) and $\mathrm{f}_{\mathrm{R} 1}$ (bottom) of the SFRC

checked for minimum shear strength according to Eq. (6); however, this expression was not governing in any of the 332 cases.

The descriptive statistics of the model error on the basis of 332 results are reported in Table 2 under the column "All results". It is worth noting that Eq. (1) provides a good estimation of experimental results (especially considering that $f_{\mathrm{R} i}$ values were computed using a regression to experimental results) with a magnitude of scatter similar to that obtained by other researchers. Subsequently, a box-and-whiskers plot was used to eliminate outliers, i.e., values of $\delta$ smaller than $Q_{1}-1.5 \cdot I Q R$ and greater than $Q_{3}+1.5 \cdot I Q R$ were excluded (where $Q_{1}$ and $Q_{3}$ are the first and third quartile, respectively, and $I Q R$ is the "interquartile range", i.e. $Q_{3}-Q_{1}$ ). In this way, a total of five $\delta$ values were excluded (one below the limit and four above), leading to a new average of $\delta$ of 1.075 and $\mathrm{CoV}$ of $22.8 \%$, as reported in Table 2 under the "Outliers excluded" column. Therefore, the outliers have a minimal effect on the results.

Finally, the model error $\delta$ (with excluded outliers) distribution was checked using Q-Q plots against the
Table 2 Summary statistics of the model error $\delta$

\begin{tabular}{lcc}
\hline & $\begin{array}{l}\text { All results } \\
n=332\end{array}$ & $\begin{array}{l}\text { Outliers excluded } \\
n=327\end{array}$ \\
\hline Mean, $\mu$ & 1.081 & 1.075 \\
Standard deviation, $\sigma$ & 0.258 & 0.245 \\
$\operatorname{CoV}(\%)$ & 23.8 & 22.8 \\
\hline
\end{tabular}

normal and log-normal distributions, Fig. 3. It can be seen from Fig. 3 that $\delta$ is better approximated by a normal distribution in the range $\delta>1.6$, whilst for $\delta<1.0$, the lognormal distribution provides a better estimation. Since the latter range is the most relevant for partial factor calibration, the lognormal distribution was found to be the most representative for this purpose.

\section{Calibration of the FRC partial factor for shear design}

\subsection{Design set}

To assess the achieved reliability index of the model described in Sect. 2.1, a set of design cases was defined and an approach similar to the one adopted by Zeng et al. [46] was followed. The set should provide a range of design parameters representative of the intended applications. In this research, it was considered that the target applications of the FRC beam without transversal reinforcement are building and bridge-deck slabs, beams, footings, and mat foundations, among others. The typical range of thicknesses of these elements lies within 200 to $1000 \mathrm{~mm}$, while normal to high strength concrete classes, and reinforcement ratios can be used. The values of the design variables considered in the design set are shown in Table 3.

Notice that the cross-section width $b$ was considered fixed at $300 \mathrm{~mm}$ as the model depends linearly on $b$, i.e. any variation of this parameter would produce a proportional variation on the predicted strength. Therefore, the probability of failure is insensitive to variations of $b$. Similarly, the effective concrete cover (d') was taken as $50 \mathrm{~mm}$ in all cases; hence, the effective depth being $d=h-d^{\prime}=h-50 \mathrm{~mm}$. The variables in Table 3 produce 140 combinations of 

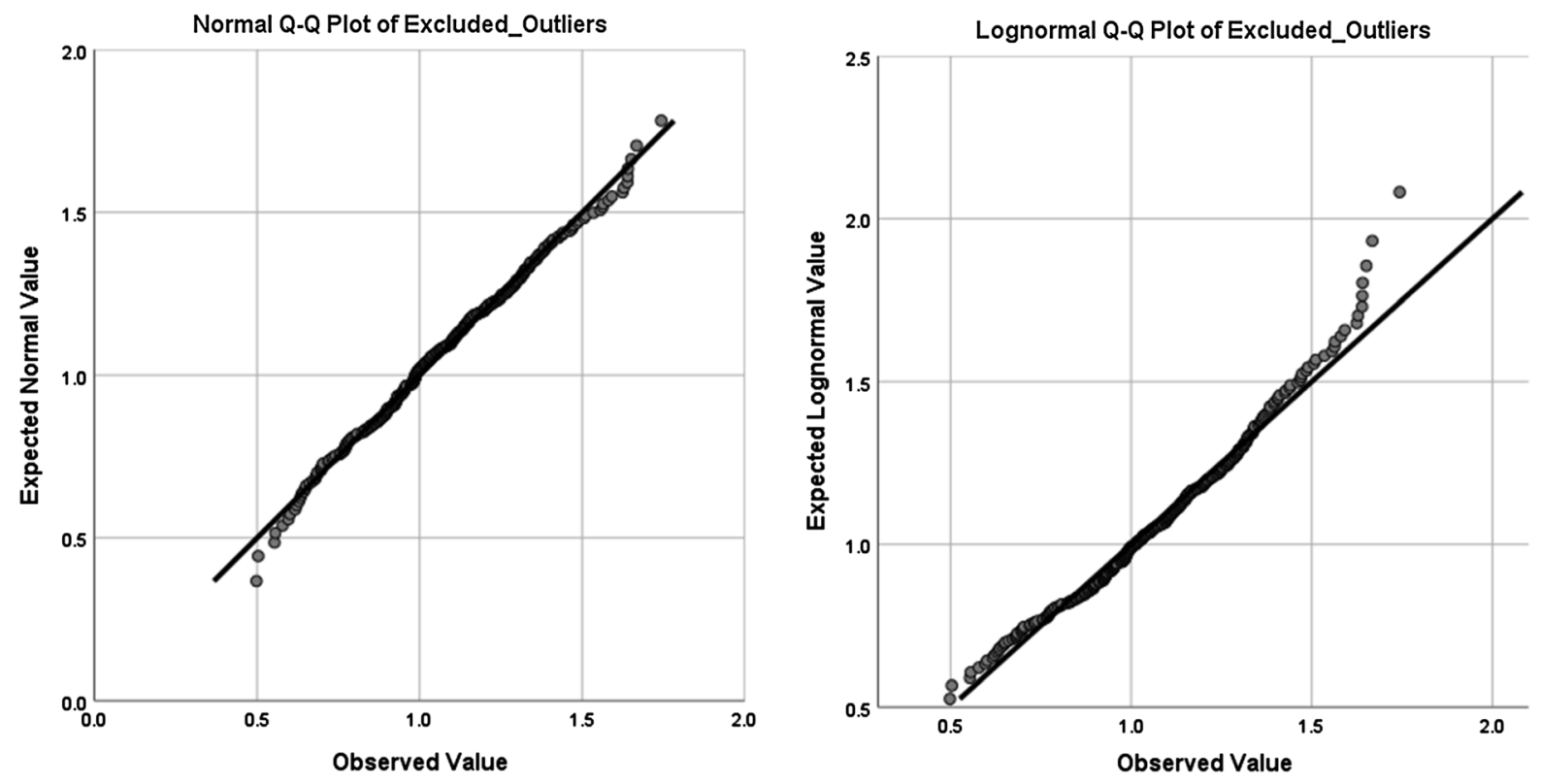

Fig. 3 Q-Q plots for the model error $\delta$ considering the normal (left) and lognormal (right) distributions

geometry, longitudinal reinforcement and concrete class.

The design loads for each element of the design set were obtained through the procedure summarized in Fig. 4, in order to have design loads that are consistent with each specimen geometry and the practical applications of FRC without shear reinforcement. Each type of specimen is assessed for a set of five load levels, within a suitable range of values. The first step is to compute the minimum and maximum load level for each geometry, and combination of material properties of Table 3 . In order to make sure that the selected range of values is representative of the actual applications, the element capacity according to the current code provisions is taken as reference, with an associated lower and upper residual flexural capacity; taken as $f_{\mathrm{R} 3 \mathrm{k}, \text { min }}=3 \mathrm{MPa}$ and $f_{\mathrm{R} 3 \mathrm{k}, \max }=10 \mathrm{MPa}$, respectively. The corresponding value of $f_{\mathrm{R} 1 \mathrm{k}}$ was estimated by means of the regression developed in Fig. 2b. Further, the reference minimum and maximum design loads of the range are computed using the current code model, described in Sect. 2.1, and the current code safety factor $\gamma_{c}=1.50$. It must be remarked that $f_{\mathrm{R} 3 \mathrm{k}}$ larger than $10 \mathrm{MPa}$ is rarely found in practice for the structural elements that are intended to be covered in this analysis.

The range was further divided, so that five design loads were obtained for each case. Considering the 5 design loads, a total of 700 design cases $(140 \times 5)$ were generated. The histogram of the design load, in terms of average shear stress $v_{\mathrm{d}}=V_{\mathrm{d}} /(b \cdot d)$, is shown in Fig. 5. The design shear stresses vary between 0.5 and 2.7 MPa, with an average value of $1.5 \mathrm{MPa}$.

\subsection{Probability analysis}

The reliability of each design case was assessed by means of the reliability index $\beta$, which is related to the probability of failure $\left(P_{\mathrm{f}}\right)$ through Eq. (10), where $\Phi$ is the cumulative standard normal distribution. FORM
Table 3 Range of variables in the design set

\begin{tabular}{|c|c|c|c|c|c|c|c|}
\hline \multirow{2}{*}{$\frac{\text { Parameter }}{b(\mathrm{~mm})}$} & \multicolumn{7}{|c|}{ Values of parameters in the design set } \\
\hline & 300 & & & & & & \\
\hline$h(\mathrm{~mm})$ & 200 & 400 & 600 & 800 & 1000 & & \\
\hline$\rho_{1}(-)$ & 0.002 & 0.005 & 0.010 & 0.015 & 0.020 & 0.025 & 0.030 \\
\hline$f_{\mathrm{ck}}(\mathrm{MPa})$ & 30 & 50 & 70 & 90 & & & \\
\hline
\end{tabular}




$$
\begin{aligned}
& \text { Define } v_{d, \min }: \\
& \text { Take } f_{F t u k}=1 \mathrm{MPa} \text { and } \gamma_{c}=1.5 \\
& v_{d, \min }=\frac{0.18}{\gamma_{c}} k\left[100 \rho_{l}\left(1+7.5 \frac{f_{F t u k}}{f_{c t k}}\right) f_{c k}\right]^{\frac{1}{3}} \geq 0.035 \sqrt{k^{3} f_{c k}}
\end{aligned}
$$

Define $v_{d, \text { max }}$ :

Take $f_{\text {Ftuk }}=3.33 \mathrm{MPa}$ and $\gamma_{c}=1.5$

$v_{d, \max }=\frac{0.18}{\gamma_{c}} k\left[100 \rho_{l}\left(1+7.5 \frac{f_{F t u k}}{f_{c t k}}\right) f_{c k}\right]^{\frac{1}{3}} \geq 0.035 \sqrt{k^{3} f_{c k}}$

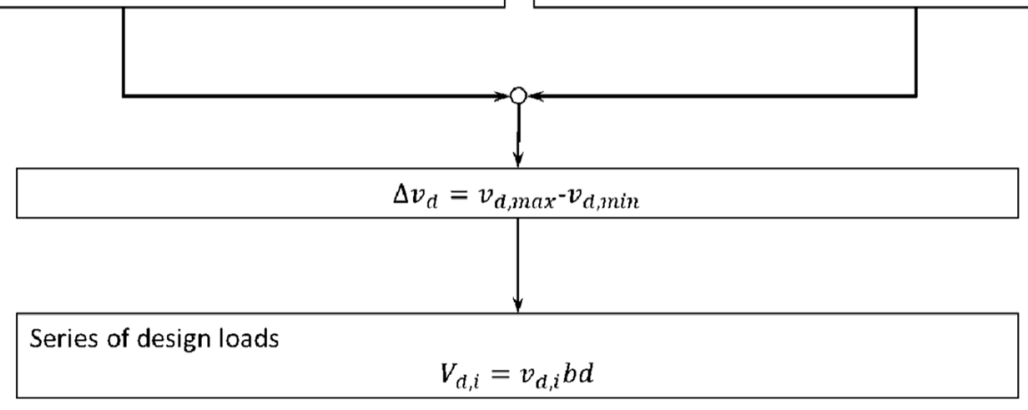

Fig. 4 Summary of procedure for obtaining the design loads for each element of the design set

$[47,48]$ was selected to estimate the reliability index as this method provides an adequate balance between precision and computation cost for small values of probability of failure, as is the case in ultimate limit state situations.

$\beta=-\Phi^{-1}\left(P_{\mathrm{f}}\right)$

A design failure is identified when a negative value is found in the limit state function $(G)$ shown in Eq. (11).

$G=V_{\mathrm{R}}-V_{\mathrm{S}}$

$V_{\mathrm{R}}=\delta \cdot V_{\mathrm{R}, \text { model }}$

In Eq. (12), $\delta$ is the model error, Eq. (8); $V_{\mathrm{R} \text {,model }}$ is the shear resistance predicted by the model (i.e. $V_{\mathrm{R}}$ is the shear resistance based on the model prediction and

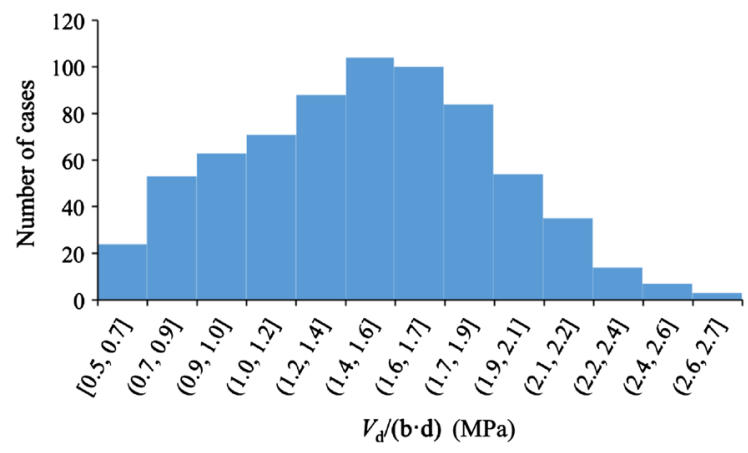

Fig. 5 Histogram of design load shear stress $v_{\mathrm{d}}=V_{\mathrm{d}}$ / $(b \cdot d)(\mathrm{MPa})$ model error); and $V_{\mathrm{S}}$ is the applied shear load (load to be resisted).

Considering $G$ a function of random variables, the probability of failure is computed as the probability of obtaining a negative value of $G$, see Eq. (13).

$P_{f}=P(G<0)=P\left(\delta \cdot V_{\mathrm{R}}-V_{\mathrm{S}}<0\right)$

$V_{\mathrm{R} \text {,model }}$ was selected as the same model described in Sect. 2.1, without the safety factor and using the observed values of the materials and geometry variables. By applying Eqs. (14)-(16), the $V_{\mathrm{R} \text {,model }}$ for elements without axial forces can be computed for a given realization of design random variables.

$V_{\mathrm{R}, \text { model }}=\tau_{\mathrm{R}} \cdot\left(b_{\mathrm{w}}+\Delta \mathrm{b}\right) \cdot(d+\Delta d)$

$\tau_{\mathrm{R}}=0.18 \cdot k \cdot\left[100 \cdot \rho_{1} \cdot\left(1+7.5 \cdot \frac{f_{\mathrm{Ftu}}}{f_{\mathrm{ct}}}\right) \cdot f_{\mathrm{c}}\right]^{1 / 3} \geq 0.035 \sqrt{k^{3} f_{\mathrm{c}}}(\mathrm{MPa})$

$k=1+\sqrt{\frac{200}{(d+\Delta d)(\mathrm{mm})}} \leq 2.0$

The set of random variables and the corresponding distribution functions used are summarized in Table 4. The model error $\delta$ was selected as lognormal distributed according to the recommendations of the Joint Committee on Structural Safety (JCSS) [49]. In Sect. 2.2.2, this distribution was shown to provide better approximation to the values of $\delta<1$ than for a normal distribution. The mean and $\mathrm{CoV}$ values imposed were those found in Sect. 2.2.2. 
Similarly, the concrete compression, tension, and the residual tensile strengths were represented by lognormal distributions (without negative values of the variables) following the recommendations of the JCSS [49]. The mean value of the compression and tension strength were computed, for the different concrete classes in the design set, according to current code provisions. The $\mathrm{CoV}$ of compression strength was selected to maintain the relationship $f_{\mathrm{cm}}=f_{\mathrm{ck}}+$ $8 \mathrm{MPa}$ (see Table 4), using a log-normal distribution. Concretely, the CoV values used for the values of $f_{\text {ck }}$ $30,50,70$, and $90 \mathrm{MPa}$ were $13.8 \%, 8.8 \%, 6.5 \%$, and $5.1 \%$, respectively. The value of $f_{\mathrm{Ftu}}$ was defined as in Eq. (4). As for $f_{\mathrm{R} 1}$ and $f_{\mathrm{R} 3}$, the relationships between the mean and characteristic values of those are dependent on both the type and amount of fibres; nevertheless, the different databases and reports converge in that a $20 \%$ of $\mathrm{CoV}$ can be representative of the dispersion of these variables [45, 50]. The relationship between the average and characteristic values of $f_{\mathrm{R} i}$ were computed consistently with this $\mathrm{CoV}$. Nevertheless, since $\mathrm{CoV}$ of $f_{\mathrm{R} i}$ is a relevant parameter for both quality control and design of FRC elements, the results of a sensitivity analysis carried out to quantify the effect of $\operatorname{CoV}_{\mathrm{fRi}}$ on $\beta$ and $\gamma_{\mathrm{c}}$ are presented in Sect. 3.4.

Finally, geometry errors were modelled by imposing deviations of the section width $(\Delta b)$ and effective depth $(\Delta d)$ according the tolerances accepted in the codes. These errors were assumed to be normally distributed with an average and $\mathrm{CoV}$ defined by the JCSS [49].

\subsection{Resistance partial factor}

Safety factors can be calibrated based on a uniform target reliability index imposed in a design set. Several authors, such as Melchers [47], Madsen et al. [48], Casas [51], and Bairan and Casas [52] already applied successfully this approach.

To establish the relationship between $\gamma_{\mathrm{c}}$ and $\beta$, the required $f_{\text {Ftu }}$ has to be designed for each element belonging to the design set of Sect. 3.1, for different values of $\gamma_{\mathrm{c}}$. For this purpose, the design equation Eq. (17) was imposed, where $V_{\mathrm{Rd}}$ corresponds to the resistance equation described in Sect. 2.1 and $V_{\mathrm{Sd}}$ is the design shear load. The reliability index of each element is then computed, as described in Sect. 3.2.

$V_{\mathrm{Rd}}=V_{\mathrm{Sd}}$

In general, the calibration process should consider both resistance and load parameters as random variables, as considered in references [47, 48, 51, 52]. This would produce specific sets of partial factors for different types of loads considered. However, under the assumption of loads and resistance as independent random variables, it is possible to calibrate the resistance safety factor independently, by assuming the load as deterministic and using an adequate sensitivity factor for the resistance random variable $\left(\alpha_{\mathrm{R}}\right)$.

The design shear load $V_{\mathrm{Sd}}$ was assumed to be deterministic; therefore, the computed reliability index refers to the probability of reaching a shear strength $\left(V_{\mathrm{R}}\right)$ smaller than the design resistance $\left(V_{\mathrm{Rd}}\right)$,

Table 4 Definition and distribution of random variables

\begin{tabular}{lllll}
\hline Variable & Description & Statistical model & Mean value $(\mu)$ & CoV \\
\hline$\delta$ & Model error & Lognormal & 1.075 & 0.228 \\
$f_{\mathrm{c}}$ & Compression strength & Lognormal & $f_{\mathrm{ck}}+8 \mathrm{MPa}$ & $0.05-0.128$ \\
$f_{\mathrm{ct}}$ & Tensile strength & Lognormal & $f_{\mathrm{ck}} \leq 50 \mathrm{MPa} \rightarrow 0.3 f_{\mathrm{ck}}^{\frac{2}{3}}$ & 0.182 \\
& & & $f_{\mathrm{ck}}>50 \mathrm{MPa} \rightarrow$ & $2.12 \ln \left(1+\frac{f_{\mathrm{cm}}}{10}\right)$ \\
& & & $1.412 f_{\mathrm{Ftuk}}$ & 0.2 \\
$f_{\text {Ftu }}$ & Residual strength of CMOD $=1.5 \mathrm{~mm}$ & Lognormal & $0.003 \cdot b \leq 3 \mathrm{~mm}$ & $4+0.006 \cdot b \leq 10 \mathrm{~mm}$ \\
$\Delta b$ & Geometrical error in section width & Normal & $10 \mathrm{~mm}$ & 1 \\
$\Delta d$ & Geometrical error in effective depth & Normal & & \\
\hline
\end{tabular}


see Eq. (18). Consequently, the obtained resistance reliability index is then referred as $\beta_{\mathrm{R}}$.

$P\left(V \leq V_{\mathrm{Rd}}\right)=\Phi\left(\beta_{\mathrm{R}}\right)$

The reliability index associated to the model proposed in the $f i b$ Model Code2010 for estimating the shear strength capacity of FRC members without shear reinforcement [Eq. (1)] was assessed for a range of safety factors varying between 1.10 and 2.50 (see Fig. 6).

As it can be observed in Fig. 6 , the obtained $\beta_{\mathrm{R}}$ vary within $0.96\left(\gamma_{c}=1.10\right)$ and $4.32\left(\gamma_{c}=2.50\right)$, with the $\beta_{\mathrm{R}}$ for $\gamma_{\mathrm{c}}=1.50$ proposed in the fib MC2010 being 2.25 .

In general, the target reliability index can be established as a result derived from an analysis coupling economic costs and failure consequences for human beings. As reference, a target reliability index for ULS verifications for a period of 50 years and medium consequences of failure of $\beta_{\text {target }}=3.8$ is suggested in the $f i b$ Model Code 2010. Additionally, $\beta_{\text {target }}$ of 3.1 and 4.3 are suggested in the same code for low and high consequences of failure, respectively, for a period of 50 years.

It should be noticed that $\beta_{\text {target }}$ accounts for uncertainties associated with both resistance and loads, as random variables, whereas $\beta_{\mathrm{R} \text {,target }}$ includes only those associated with the resistance. However, it may be assumed that the $\beta_{\text {target }}$ and $\beta_{\mathrm{R} \text {,target }}$ are linearly related through the resistance sensitivity coefficient $\left(\alpha_{\mathrm{R}}\right)$, see Eq. (19).

$\beta_{\mathrm{R}, \text { target }}=\alpha_{\mathrm{R}} \cdot \beta_{\text {target }}$

The resistance $\left(\alpha_{R}\right)$ and load $\left(\alpha_{E}\right)$ sensitivity coefficients can be considered as 0.8 and -0.7 ,

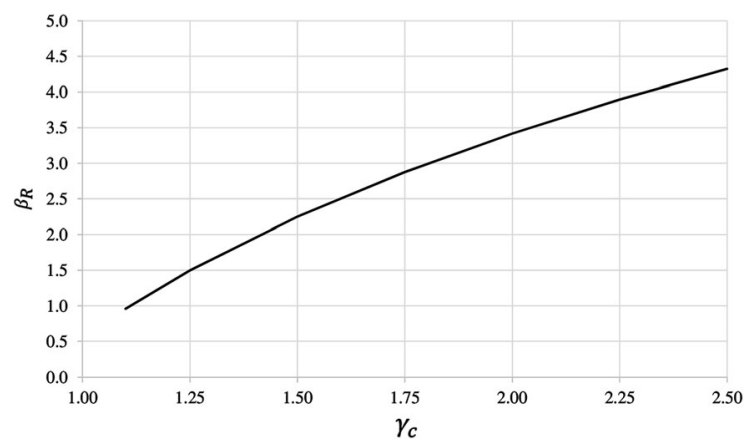

Fig. 6 Variation of the resistance reliability index with respect to the safety factor respectively, provided that the ratio of their standard deviations satisfies the condition $0.16<\sigma_{\mathrm{E}} / \sigma_{\mathrm{R}}<7.6$ [53].

Table 5 gathers the $\beta_{\text {target }}$ for the three reference consequences of failure defined in MC2010, together with the computed $\gamma_{\mathrm{c}}$ required to guarantee these $\beta_{\text {target }}$ in the design set. For the reference consequence of failure $\left(\beta_{\text {target }}=3.8\right)$, the required $\gamma_{c}$ is 1.82 , which is $21 \%$ larger than that currently proposed in the code $\left(\gamma_{\mathrm{c}}=1.50\right)$.

An alternative approach to ensure the required reliability avoiding the use of $\gamma_{c}$ different from 1.50 (accepted in the codes and widely used) consists in adapting the coefficient $C_{\mathrm{Rd}, \mathrm{c}}$ implicitly included in Eq. (1) as $0.18 / \gamma_{c}$, accordingly. Moreover, other failure consequences different from moderate (referenced in MC2010) may be considered by multiplying the partial factors of the unfavourable loads by a factor $K_{\mathrm{FI}}$, this approach being the one recommended in Eurocode 0 [53].

The values of $C_{\mathrm{Rd}, \mathrm{c}}$ and $K_{\mathrm{FI}}$ that guarantee the $\beta_{\text {target }}$ associated to each failure consequence class are presented in Table 6. Based on the results of Table 7, it can be remarked that modifying the original value of $C_{\mathrm{Rd}, \mathrm{c}}=0.18 / \gamma_{\mathrm{c}}$ to $0.15 / \gamma_{\mathrm{c}}$ (for FRC elements), $\gamma_{\mathrm{c}-}$ $=1.50$ can be considered while reaching $\beta_{\text {target }}$ aligned with the fib MC2010 structural reliability level. Likewise, it should be highlighted that the $K_{\mathrm{FI}}$ obtained are similar to those recommended in Eurocode 0 [53].

$V_{\mathrm{Rd}, \mathrm{F}}=\left\{C_{\mathrm{Rd}, \mathrm{c}} \cdot k \cdot\left[100 \cdot \rho_{1} \cdot\left(1+7.5 \cdot \frac{f_{\mathrm{Ftuk}}}{f_{\mathrm{ctk}}}\right) \cdot f_{\mathrm{ck}}\right]^{1 / 3}+0.15 \cdot \sigma_{\mathrm{cp}}\right\} \cdot b_{\mathrm{w}} \cdot d$

\subsection{Sensitivity analysis}

In addition to the estimation of the reliability index, the FORM analysis allows computing the vector of sensitivity vectors $(\boldsymbol{\alpha})$ in the design point. Namely, $\boldsymbol{\alpha}$ is a unit length vector with one component per random variable. The value of sensitivity factor indicates the relative contribution of the random variable to the failure probability.

Figure 7 shows the probability distribution function (PDF) of the components of the sensitivity factor for the design set considered. As it can be noticed, the sensitivity factor component of the variable that 
Table 5 Safety factors for the target reliability of different consequences of failure

\begin{tabular}{lllr}
\hline Consequence of failure & $\beta_{\text {target }}$ & $\begin{array}{l}\alpha_{\mathrm{R}} \cdot \beta_{\text {target }} \\
\left(\text { taking } \alpha_{\mathrm{R}}=0.8\right)\end{array}$ & $\gamma_{\mathrm{c}}$ \\
\hline Low & For 50 years & 2.48 & 1.59 \\
Moderate & 3.1 & 3.04 & 1.82 \\
High & 3.8 & 3.44 & 2.01 \\
\hline
\end{tabular}

Table 6 Coefficients affecting the FRC shear resistance and load factors using constant $\gamma_{\mathrm{c}}$

\begin{tabular}{llll}
\hline Consequence of failure & $\gamma_{\mathrm{c}}$ & $C_{\mathrm{Rd}, \mathrm{c}}$ & $K_{\mathrm{FI}}$ \\
\hline Low & 1.50 & $0.15 / \gamma_{\mathrm{c}}$ & 0.88 \\
Moderate & 1.50 & $0.15 / \gamma_{\mathrm{c}}$ & 1.01 \\
High & 1.50 & $0.15 / \gamma_{\mathrm{c}}$ & 1.12 \\
\hline
\end{tabular}

Table 7 Coefficient $C_{\mathrm{Rd}, \mathrm{c}}$ by varying $\mathrm{CoV}$ of $f_{\mathrm{Ftu}}$

\begin{tabular}{lll}
\hline$f_{\mathrm{Ftu}} \mathrm{CoV}=10 \%$ & $f_{\mathrm{Ftu}} \mathrm{CoV}=20 \%$ & $f_{\mathrm{Ftu}} \mathrm{CoV}=30 \%$ \\
\hline$C_{\mathrm{Rd}, \mathrm{c}}=0.094$ & $C_{\mathrm{Rd}, \mathrm{c}}=0.098$ & $C_{\mathrm{Rd}, \mathrm{c}}=0.101$ \\
\hline
\end{tabular}

simulates the model error $(\delta)$ lies within 0.88 and 0.98 ; hence, this is the variable with the highest influence on the computed reliability. The assumption of different coefficient of variation $(\mathrm{CoV})$ of $\delta$, within typical values, shows that the sensitivity of $\delta$ does not vary significantly; being the average sensitivity factor 0.92 , 0.94 and 0.96 for CoV 0.3, 0.2 and 0.1, respectively. The other variables to which the probability of failure shows larger sensitivity are the tensile strength $\left(f_{\mathrm{ct}}\right)$ and the residual strength $\left(f_{\mathrm{Ftu}}\right)$.

The sensitivity factor of $f_{\mathrm{ct}}$ is relatively stable in the range of -0.25 to -0.20 . The negative values in this case indicates that a higher value of the variable tends to reduce the resistance, which could be expected from the type of model in Eq. (15), where $f_{\mathrm{ct}}$ is in the denominator. Figure 8 shows the PDF of the ratios of the variable value in the design point over their corresponding average. As can be seen in Fig. 8, value of the $f_{\mathrm{ct}}$ in the design point is around $10 \%$ larger than the average. This suggests that the use of the $5 \%$ characteristic value of $f_{\text {ctk }}$ in the design formulation is not conservative, whereas using the average strength seems more adequate. Nevertheless, for the sake of simplicity of the formulation, it is preferred here to keep the same type of design reference values (characteristic) and calibrate the safety factor accordingly.

Similarly, Fig. 7 allows stating that the contribution of the residual strength $\left(f_{\text {Ftu }}\right)$ to the probability of failure varies with $\mathrm{CoV}$ in the opposite way as the model error; i.e. the lower the $\mathrm{CoV}$, the lower the sensitivity factor of $f_{\mathrm{Ftu}}$. Figure 8 indicates that the values of $f_{\mathrm{Ftu}}$ at the design point vary between 0.75 and 0.98 of the average value. This is consistent with using the $5 \%$ characteristic value in the design equation.

Table 7 reports the reliability index of the resistance for different CoVs of $f_{\mathrm{Ftu}}$, when designed according to the safety format of Eq. (20) and Table 6, for moderate failure consequences. It can be seen that the resistance reliability index reduces by $6 \%$ when varying from $\mathrm{CoV}$ of $20 \%$ to $10 \%$, whereas it increases by $2 \%$ when the $\mathrm{CoV}$ of the residual strength increases from 20 to $30 \%$.

Although this variation might seem counterintuitive at a first glance, it can be explained by the lower contribution of $f_{\mathrm{Ftu}}$ to reliability at the design point when its $\mathrm{CoV}$ is reduced, see Fig. 7. Accordingly, the sensitivity to the model error increases and compensates the lower dispersion of $f_{\mathrm{Ftu}}$. Nevertheless, the above variation of the reliability index is small; therefore, the recommended values of the safety format coefficients are those given in Table 6, which refer to a typical value of $\mathrm{CoV}$ of $20 \%$.

\section{Conclusions}

This paper presented a comprehensive reliabilitybased calibration of the partial factor $\gamma_{c}$ for the shear design of FRC members without shear reinforcement according to the $f i b$ Model Code 2010 model. For this purpose, a database of experimental results was used for assessing the model error, after which a FORM 

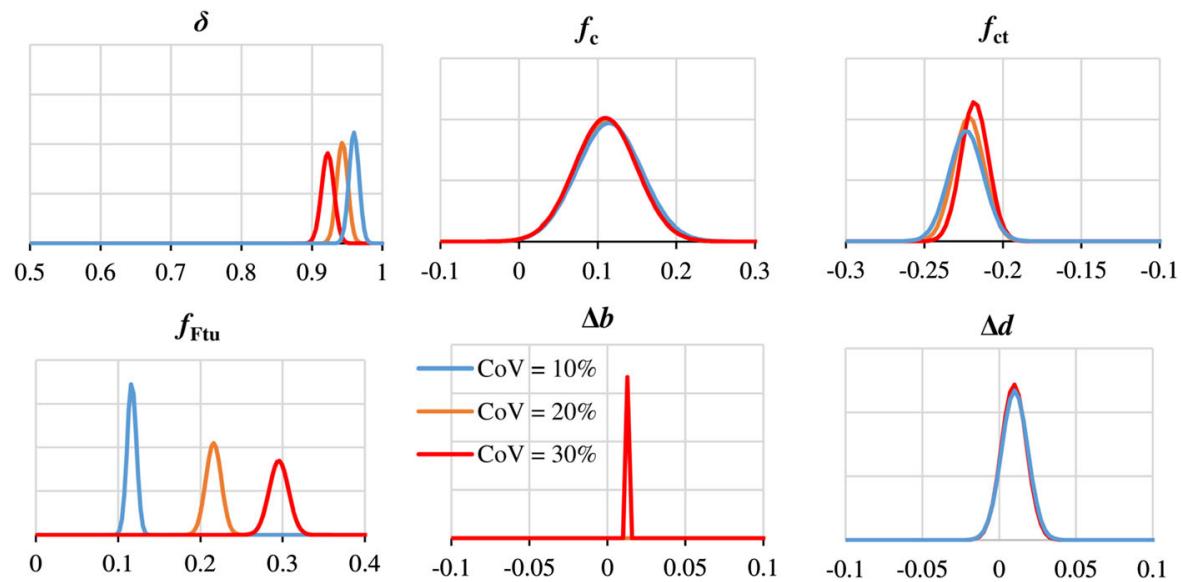

Fig. 7 PDF of the sensitivity of the components of the importance vector (the horizontal axis represents the sensitivity factor for each variable)

$\delta$

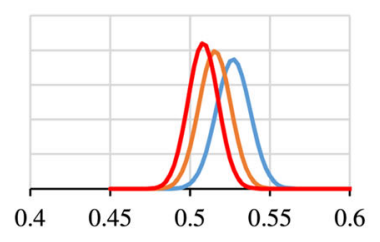

$f_{\text {Ftu }}$

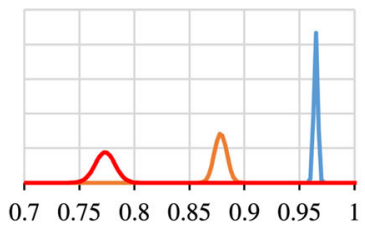

$f_{\mathrm{c}}$

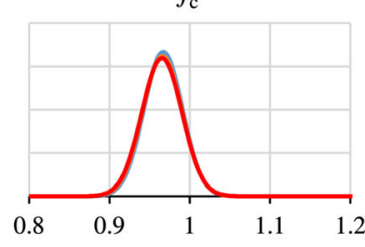

$\Delta b$

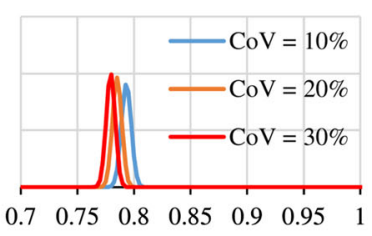

$f_{\mathrm{ct}}$

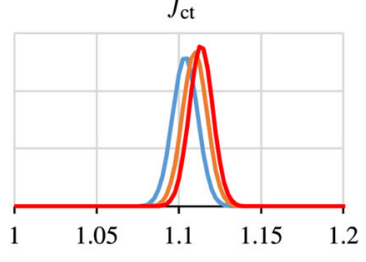

$\Delta d$

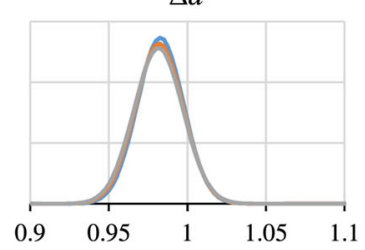

Fig. 8 PDF of the ratio of value at the design point over the mean (the horizontal axis represents the variable value at the design point divided by the variable's mean)

analysis was conducted to calibrate the partial factor. Based on the obtained results, the following conclusions can be drawn:

- The model error of the $f i b \mathrm{MC} 2010$ shear resistance model for members without shear reinforcement was determined to be lognormally distributed with a mean of 1.075 and $\mathrm{CoV}$ of $22.8 \%$ based on 332 experimental results.

- Based on a probability analysis and a parametric study of 700 individual cases, the relationship between the target failure probability $\beta_{\mathrm{R}}$ and partial factor $\gamma_{\mathrm{c}}$ was determined. It was found that $\beta_{\mathrm{R}}$ associated with the value of $\gamma_{\mathrm{c}}=1.50$ currently adopted in MC2010-is 2.25 , i.e. below the target values of $\alpha_{R} \cdot 3.1=2.48 ; \alpha_{R} \cdot 3.8=3.04$ and $\alpha_{\mathrm{R}} \cdot 4.3=3.44$ associated with low, moderate and high consequences of failure, respectively, and a service life of 50 years, considering the resistance sensitivity coefficient as $\alpha_{R}=0.8$.

- The results of the study show that it is possible to achieve the target values of $\beta_{\mathrm{R}}$ by maintaining $\gamma_{\mathrm{c}}=1.50$ but reducing the coefficient $C_{\mathrm{Rd}, \mathrm{c}}$ in the resistance equation from $0.18 / \gamma_{c}$ to $0.15 / \gamma_{c}$. This modification is consistent to with failure consequence factors $K_{\mathrm{FI}}$ for unfavourable loads equal to $0.88,1.01$ and 1.12 for low, moderate and high consequences of failure, respectively; which is consistent with the current values recommended in Eurocode 0 (EN1990). 
- The variable that most influences the reliability in the design point is the model error of the design formulation which partially compensates the variation of the $\mathrm{CoV}$ of the residual strength within common typical values. Therefore, the recommended values of $\gamma_{\mathrm{c}}=1.50$ and $C_{\mathrm{Rd}, \mathrm{c}}=0.15 / \gamma_{\mathrm{c}}$ can be considered constant for the range of $\mathrm{CoV}$ of $f_{\mathrm{Ftu}}$ between 10 and $30 \%$.

The results of this study allow confirming that target failure probabilities could not be achieved by the MC2010 model for the shear resistance of FRC members without shear reinforcement with $\gamma_{c}=1.50$. Therefore, calibration of the partial factor is required for future code revisions. Nonetheless, the results of the study are dependent on the range of parameters considered in the experimental database used for assessing the model error and on the choice of parameter ranges in the probability analysis. However, these can be considered as robust enough for drawing general conclusions.

Funding Open Access funding provided thanks to the CRUECSIC agreement with Springer Nature. This study has received funding from the European Union's Horizon 2020 research and innovation programme under the Marie Sklodowska-Curie grant agreement No 836270. This support is gratefully acknowledged. The authors also wish to express their acknowledgement to the Ministry of Economy, Industry and Competitiveness of Spain for the financial support received under the scope of the projects PID2019-108978RB-C32. Any opinions, findings, conclusions, and/or recommendations in the paper are those of the authors and do not necessarily represent the views of the individuals or organizations acknowledged.

Availability of data and material The datasets generated during and/or analysed during the current study are available in the Mendeley Data repository, http://dx.doi.org/10.17632/ khvn8nw2np.1.

Code availability Not applicable.

\section{Declaration}

Conflict of interest The authors declare that they have no conflict of interest.

Open Access This article is licensed under a Creative Commons Attribution 4.0 International License, which permits use, sharing, adaptation, distribution and reproduction in any medium or format, as long as you give appropriate credit to the original author(s) and the source, provide a link to the Creative Commons licence, and indicate if changes were made. The images or other third party material in this article are included in the article's Creative Commons licence, unless indicated otherwise in a credit line to the material. If material is not included in the article's Creative Commons licence and your intended use is not permitted by statutory regulation or exceeds the permitted use, you will need to obtain permission directly from the copyright holder. To view a copy of this licence, visit http://creativecommons.org/licenses/by/4.0/.

\section{References}

1. de la Fuente A, Blanco A, Armengou J, Aguado A (2017) Sustainability based-approach to determine the concrete type and reinforcement configuration of TBM tunnels linings. Case study: extension line to Barcelona Airport T1. Tunn. Undergr. Sp. Technol. 61:179-188. https://doi.org/ 10.1016/j.tust.2016.10.008

2. de La Fuente A, Casanovas-Rubio MDM, Pons O, Armengou J (2019) Sustainability of column-supported RC slabs: fiber reinforcement as an alternative. J Constr Eng Manag 145:1-12. https://doi.org/10.1061/(ASCE)CO.1943-7862. 0001667

3. FIB Bulletin 83 (2018) Precast Tunnel Segments in FibreReinforced Concrete. International Federation for Structural Concrete (fib), Lausanne

4. Roesler JR, Altoubat SA, Lange DA et al (2006) Effect of synthetic fibers on structural behavior of concrete slabs-onground. ACI Mater J 103:3-10. https://doi.org/10.14359/ 15121

5. Meda A, Plizzari GA, Riva P (2004) Fracture behavior of SFRC slabs on grade. Mater. Struct. Constr. 37:405-411. https://doi.org/10.1617/14093

6. Meda A, Plizzari GA (2004) New design approach for steel fiber-reinforced concrete slabs-on-ground based on fracture mechanics. ACI Struct J 101:298-303. https://doi.org/10. 14359/13089

7. Chen S (2007) Steel fiber concrete slabs on ground: a structural matter. ACI Struct J 104:373-375

8. Caratelli A, Meda A, Rinaldi Z, Romualdi P (2011) Structural behaviour of precast tunnel segments in fiber reinforced concrete. Tunn. Undergr. Sp. Technol. 26:284-291. https://doi.org/10.1016/j.tust.2010.10.003

9. Chiaia B, Fantilli AP, Vallini P (2007) Evaluation of minimum reinforcement ratio in FRC members and application to tunnel linings. Mater. Struct. Constr. 40:593-604. https:// doi.org/10.1617/s11527-006-9166-0

10. Chiaia B, Fantilli AP, Vallini P (2009) Combining fiberreinforced concrete with traditional reinforcement in tunnel linings. Eng Struct 31:1600-1606. https://doi.org/10.1016/j. engstruct.2009.02.037

11. De la Fuente A, Pujadas P, Blanco A, Aguado A (2012) Experiences in Barcelona with the use of fibres in segmental linings. Tunn. Undergr. Sp. Technol. 27:60-71. https://doi. org/10.1016/j.tust.2011.07.001

12. Plizzari GA, Tiberti G (2006) Steel fibers as reinforcement for precast tunnel segments. Tunn. Undergr. Sp. Technol. 21:438-439. https://doi.org/10.1016/j.tust.2005.12.079

13. Winkler, A., Edvardsen, C. and Kasper, T.: Examples of bridge, tunnel lining and foundation design with Steel-fibrereinforced concrete. In: American Concrete Institute, ACI Special Publication. pp. 451-460 (2014) 
14. Parra-Montesinos, G.J., Wight, J.K., Kopczynski, C., et al.: Earthquake-resistant fibre-reinforced concrete coupling beams without diagonal bars. In: American Concrete Institute, ACI Special Publication. pp. 461-470 (2014)

15. Massicotte, B.: High performance fibre reinforced concrete for structural applications. In: 3rd FRC International Workshop Fibre Reinforced Concrete: from Design to Structural Applications. Desenzano, Lake Garda (2018)

16. Aidarov, S., de la Fuente, A., Mena, F., Ángel, S.: (2019) Campaña experimental de un forjado de hormigón reforzado con fibras a escala real. In: ACE. pp 1-10 (2019)

17. Destrée, X. and Mandl, J.: Steel fibre only reinforced concrete in free suspended elevated slabs: case studies, design assisted by testing route, comparison to the latest SFRC standard documents. In: Proceedings of the International FIB Symposium 2008-Tailor Made Concrete Structures: New Solutions for our Society. pp. 437-443 (2008)

18. Parmentier, B., Van Itterbeeck, P., Skowron, A.: The behaviour of SFRC flat slabs: the limelette full-scale experiments to support design model codes. In: American Concrete Institute, ACI Special Publication (2014)

19. Cugat V, Cavalaro SHP, Bairán JM, de la Fuente A (2020) Safety format for the flexural design of tunnel fibre reinforced concrete precast segmental linings. Tunn. Undergr. Sp. Technol. 103:103500. https://doi.org/10.1016/j.tust. 2020.103500

20. Balász, G.: A historical review of shear. In: Shear and punching shear in RC and FRC elements. In: International Federation for Structural Concrete (fib), Salò, pp. 1-14 (2010)

21. FIB Bulletin 85: Towards a rational understanding of shear in beams and slabs. Lausanne (2018)

22. EN 1992-1-1: Eurocode 2: Design of Concrete StructuresPart 1-1: General Rules and Rules for Buildings. CEN, Brussels (2004)

23. FIB: fib Model Code for Concrete Structures 2010. International Federation for Structural Concrete (fib), Lausanne (2013)

24. Vecchio FJ, Collins MP (1986) The modified compressionfield theory for reinforced concrete elements subjected to shear. J. Am. Concr. Inst. 83:219-231. https://doi.org/10. $14359 / 10416$

25. Sykora M, Holicky M, Prieto M, Tanner P (2015) Uncertainties in resistance models for sound and corrosion-damaged RC structures according to EN 1992-1-1. Mater. Struct. Constr. 48:3415-3430. https://doi.org/10.1617/ s11527-014-0409-1

26. Pacheco J, de Brito J, Chastre C, Evangelista L (2019) Uncertainty of shear resistance models: influence of recycled concrete aggregate on beams with and without shear reinforcement. Eng Struct. https://doi.org/10.1016/j. engstruct.2019.109905

27. Reineck KH, Kuchma DA, Kim KS, Marx S (2003) Shear database for reinforced concrete members without shear reinforcement. ACI Struct J 100:240-249

28. di Prisco, M., Plizzari, G. and Vandewalle, L.: MC2010: overview on the shear provisions for FRC. In: Shear and Punching Shear in RC and FRC elements2. International Federation for Structural Concrete (fib), Salò, pp. 61-76 (2010)
29. Lantsoght EOL (2019) Database of shear experiments on steel fiber reinforced concrete beams without stirrups. Materials (Basel) 12:917. https://doi.org/10.3390/ ma12060917

30. Coccia S, Meda A, Rinaldi Z (2015) On shear verification according to fib Model Code 2010 in FRC elements without traditional reinforcement. Struct Concr 16:518-523. https:// doi.org/10.1002/suco.201400026

31. Meda A, Minelli F, Plizzari GA, Riva P (2005) Shear behaviour of steel fibre reinforced concrete beams. Mater. Struct. Constr. 38:343-351. https://doi.org/10.1617/14112

32. Minelli F, Plizzari GA (2013) On the effectiveness of steel fibers as shear reinforcement. ACI Struct J 110:2013. https://doi.org/10.14359/51685596

33. Conforti A, Minelli F, Plizzari GA (2017) Shear behaviour of prestressed double tees in self-compacting polypropylene fibre reinforced concrete. Eng Struct 146:93-104. https:// doi.org/10.1016/j.engstruct.2017.05.014

34. Conforti A, Minelli F, Tinini A, Plizzari GA (2015) Influence of polypropylene fibre reinforcement and width-toeffective depth ratio in wide-shallow beams. Eng Struct 88:12-21. https://doi.org/10.1016/j.engstruct.2015.01.037

35. Minelli, F.: Plain and Fiber Reinforced Concrete Beams Under Shear Loading: Structural Behavior and Design Aspects. University of Brescia (2005)

36. Cuenca E, Conforti A, Minelli F et al (2018) A materialperformance-based database for FRC and RC elements under shear loading. Mater. Struct. Constr. 51:11. https:// doi.org/10.1617/s11527-017-1130-7

37. Marì Bernat A, Spinella N, Recupero A, Cladera A (2020) Mechanical model for the shear strength of steel fiber reinforced concrete (SFRC) beams without stirrups. Mater. Struct. Constr. 53:1-20. https://doi.org/10.1617/s11527020-01461-4

38. Matthews S, Bigaj-van Vliet A, Walraven J et al (2018) fib Model Code 2020: towards a general code for both new and existing concrete structures. Struct Concr 19:969-979

39. EN 14651 (2005) Test method for metallic fibred concrete-measuring the flexural tensile strength (limit of proportionality (LOP), residual). $\mathrm{Br}$ Stand Inst. 9780580610523

40. Lantsoght, E.: Database of experiments on SFRC beams without stirrups failing in shear (Version 1.0). Zenodo (2019)

41. Thomas J, Ramaswamy A (2007) Mechanical properties of steel fiber-reinforced concrete. J Mater Civ Eng 19:385-392. https://doi.org/10.1061/(ASCE)08991561(2007)19:5(385)

42. IS: 516 B: Methods of Test for Strength of Concrete. New Delhi (1959)

43. Venkateshwaran A, Tan KH, Li Y (2018) Residual flexural strengths of steel fiber reinforced concrete with multiple hooked-end fibers. Struct Concr 19:352-365. https://doi. org/10.1002/suco.201700030

44. Tiberti G, Germano F, Mudadu A, Plizzari GA (2018) An overview of the flexural post-cracking behavior of steel fiber reinforced concrete. Struct Concr 19:695-718. https://doi. org/10.1002/suco.201700068

45. Galeote E, Blanco A, Cavalaro SHP, de la Fuente A (2017) Correlation between the Barcelona test and the bending test in fibre reinforced concrete. Constr Build Mater 
152:529-538. https://doi.org/10.1016/j.conbuildmat.2017. 07.028

46. Zeng Y, Botte W, Caspeele R (2018) Reliability analysis of FRP strengthened RC beams considering compressive membrane action. Constr Build Mater 169:473-488. https:// doi.org/10.1016/j.conbuildmat.2018.03.019

47. Melchers RE (1987) Structural Reliability Analysis and Prediction. Ellis Horwood

48. Madsen HO, Krenk S, Lind NC (2006) Methods of Structural Safety. Dover, New York

49. JCSS: Probabilistic Model Code (2001)

50. Cavalaro SHP, Aguado A (2015) Intrinsic scatter of FRC: an alternative philosophy to estimate characteristic values. Mater. Struct. Constr. 48:3537-3555. https://doi.org/10. 1617/s11527-014-0420-6
51. Casas JR (1997) Reliability-based partial safety factors in cantilever construction of concrete bridges. J Struct Eng 123:305-312. https://doi.org/10.1061/(asce)07339445(1997)123:3(305)

52. Bairán JM, Casas JR (2018) Safety factor calibration for a new model of shear strength of reinforced concrete building beams and slabs. Eng Struct 172:293-303. https://doi.org/ 10.1016/j.engstruct.2018.06.033

53. EN 1990: Eurocode-Basis of Structural Design. CEN, Brussels (2002)

Publisher's Note Springer Nature remains neutral with regard to jurisdictional claims in published maps and institutional affiliations. 